\title{
Pattern of suicidal deaths in cases coming to tertiary center in eastern Nepal
}

\begin{abstract}
Background: Suicide is the major cause of death throughout the world. There is a relationship between mental status and social status of a person and they reflect the pattern of suicidal deaths in a particular community. Many cultural and socio-economic factors and quality of life are other contributing factors for committing suicide. Suicidal deaths happen almost everywhere in the world.
\end{abstract}

Objective: The current study was conducted to find out the causes of suicidal deaths and the various factors associated with them.

Methodology: The present study is hospital based retrospective cross-sectional study in which altogether 1701 cases were autopsied during the study period Nepali year 2062 BS to 2066 BS (14th April 2005-13th April 2010).Out of autopsied 1701 unnatural death cases 583 cases were that of the suicide which is $34.2 \%$ of total cases.

Results: There was steep rise in the cases of suicide every year. Majority of cases were of male and female of age group 11-30(53.6\%).The most common cause of death in majority of the deaths was poisoning (61.6\%) followed by hanging (33.6\%). Burn (4.6) and cut throat $(0.2)$ were methods adopted by very less number of populations. $82.8 \%$ cases were dead when were brought to hospital.

Conclusions: Treatment is of very little value in cases of suicide. So it is only the prevention which is of extreme importance to reduce the number of suicide. Effort from government agencies, proper counseling facilities for stressed individuals, adopting a healthy life style and reducing the open selling of poisonous materials will be of use in reducing suicide cases in society.

Keywords: suicidal deaths, autopsy, poisoning, hanging
Volume 4 Issue 2 - 2017

\author{
Shivendra Jha, Yadav BN, Bikash Sah \\ Department of Forensic medicine and toxicology, B.P. Koirala \\ Institute of Health Sciences, India
}

\begin{abstract}
Correspondence: Shivendra Jha, Additional Professor and Head, Department of Forensic Medicine and Toxicology, Assistant Dean (examinations), Office of the Dean, B.P. Koirala Institute of Health Sciences, Dharan, Nepal, India, Tel 97 79852049121,Email drshivendrajha@gmail.com
\end{abstract}

Received: January 31, 2017| Published: March 16, 2017

\section{Introduction}

Suicide is the intentional killing of oneself. In most states suicide is a crime, but if successful there is no one to punish. However, attempted suicide can be a punishable crime. ${ }^{1}$ Suicide is a major public health problem worldwide and is one of the major causes of mortality. According to WHO statistics, the annual worldwide incidence of completed suicide was 16 per 10000 in 1995. This accounts for $1-2 \%$ of the total global mortality. Suicide may occur for a number of reasons, including depression, shame, pain, financial difficulties, or other undesirable situations. Nearly one million people worldwide die by suicide annually, making it one of the world's leading causes of death. There are an estimated 10 to 20 million attempted suicides every year. The psychological, social and financial impact of suicide on the family and society is immeasurable. Besides the direct loss of life, there is the long lasting psychological trauma of family and friends, and the loss of economic productivity for society. ${ }^{2}$ Suicide has always been a topic of interest among researchers as there are various factors responsible to be associated with suicide. Social disorganization, poor family support system, economic imbalance, war, population explosion, scientific and technical advancement are thought to play a major role in this phenomenon. Nearly half a billion persons are reported to be taking their own lives in spite of the taboos and shame attached to the act of suicide. It is also believed that at least there are eight to ten unsuccessful or attempted suicides against each successful one. There is little national data available on the exact national suicide rates in Nepal. Only 39 countries in the world regularly report data on suicide to WHO, and Nepal is not among these. A study of suicide incidence carried out in Lalitpur district of central Nepal showed suicide rate to be $3.7 / 100000$ population year. And this may not be the actual number of cases because many cases are unreported to the authority. ${ }^{3}$ Methods of suicide are generally poisoning, burns, hanging, drowning. Previously drowning used to occupy first position of all the modes of committing suicide reported by Franklin. ${ }^{4}$

Poisoning is the major cause of suicide all over the world and being a public health problem worldwide, is one of the most common reasons for attendance at hospital emergency departments. In Nepal during fiscal year B.S. 2053/2054, ${ }^{5} 1696$ committed suicide among which second commonly adopted mode was poisoning $(n=437,25.76 \%)$. In Nepal due to depression, family disputes, illiteracy, unemployment etc. large number of people has a tendency to commit suicide and due to easy availability, poisoning is one of the most common method. Since it is used in medicine, agriculture and household works so accidental poisoning is also quite common. Hence a retrospective study of the demographic and medico-legal study was done so as to know actual number of population committing suicide, the methods used for committing suicide and the different legal aspects of it. This study focuses on suicide in relation to different parameters like age, 
sex, religion, area, days, month, duration of survival, methods applied for committing suicide etc. The study will be helpful to recognize the high risk individuals and prevent deaths by suicide.

\section{Materials and methods}

A retrospective cross-sectional study was conducted where all the cases with a clear cut history of suicide autopsied at BPKIHS during the period of BS 2062/01/01 to BS 2066/12/31 (14th April 2005 to 13th April 2010 for 5 years) were included. During this period altogether 1701 cases were autopsied at BPKIHS, Dharan mortuary out of which 583 cases were of suicide.

\section{The inclusion criteria}

All the fatal cases autopsied in BPKIHS mortuary with definite history of suicide brought during the period of 14th April 2005 to 13th April 2010.

\section{Exclusion criteria}

Cases where there is no clear history of suicide.

The detailed information about the cases was collected from different sources including:

1. The police muchulka,

2. Post-mortem entry register and

3. Post-mortem findings from the post-mortem report,

\section{Evaluation}

The details pertaining to each case were filled in proforma (questionnaire).

\section{Statistical analysis}

All collected data were entered in the Microsoft Excel Work Sheet and was analyzed using descriptive statistics in SPSS 11.5 version. The data were presented in tabulated form.

\section{Results and discussions}

Altogether 1701 cases were autopsied during the study period $14^{\text {th }}$ April 2005-13 $3^{\text {th }}$

April 2010.Out of autopsied 1701 unnatural death cases 583 cases were that of the suicide which is $34.2 \%$ of total cases. Hence we can say that suicide make one of the most common reason for unnatural deaths in this region. The results have been tabulated as follows. Table 1 shows year wise distribution of suicide from April 2005 to April 2010. Here we can see that suicide constitutes more than quarter of total unnatural death in first year of study $(29.5 \%)$ which becomes more than $2 / 5^{\text {th }}$ in last year of study $(41.4 \%)$. This is a very high percentage and is in accordance to the study by Aaron $\mathrm{R}$ et al. ${ }^{6}$ The rate of increment of suicide annually during the five year of study is an extremely alarming situation and denotes the stress level of the society Table 2 .

Present study constituted 583 cases of age range minimum 10 years to maximum 84 years. The mean age was 32.81 with a standard deviation of 15.05 . Maximum victims $(28.6 \%)$ belonged to age group $20-30$ yrs followed by age group 11-20 yrs (25\%) and 31-40yrs $(20.4 \%)$. Thus, it is observed that about three fourth of victims (74\%) were aged between $11-40$ years followed by those $(20.1 \%)$ in the age group of 41-60years.However, victims above 71 years and below 10 years have lesser prevalence being $2.1 \%$ and $0.2 \%$ respectively. Thus it revealed that males and females both is suicide victim at a younger age. This finding was consistent with the findings of Rahim $\mathrm{M}$ et al., ${ }^{7}$ Sharma BR et al., ${ }^{8}$ Srivastava AK et al., ${ }^{9}$ Dash SK $^{10}$ and Kafley et al., ${ }^{10}$ Similarly Satyavathi et al., ${ }^{12}$ and Shah, ${ }^{13}$ in their series found the highest number of fatal suicides in the age group of 20-29 years. Ramadwar et al., ${ }^{14}$ in his study found the highest incidence of fatal suicide cases in the 15-24 years age group (19.6\%) followed by $19.4 \%$ in the 25-44 years group. Gupta ${ }^{15}$ found highest number of suicide cases in the adolescent age group.

Table I Year wise distribution of victims

\begin{tabular}{|c|c|c|c|}
\hline Year & Total case & Suicide Cases & Percent \\
\hline $\begin{array}{l}\text { I4th April 2005-13th April } \\
2006\end{array}$ & 281 & 83 & 29.5 \\
\hline $\begin{array}{l}\text { 14th April 2006-13th April } \\
2007\end{array}$ & 294 & 89 & 30.2 \\
\hline $\begin{array}{l}\text { 14th April 2007-I3th April } \\
2008\end{array}$ & 314 & 104 & 33.1 \\
\hline $\begin{array}{l}\text { 14th April 2008-13th April } \\
2009\end{array}$ & 336 & 110 & 32.7 \\
\hline $\begin{array}{l}\text { 14th April 2009-13th April } \\
2010\end{array}$ & 476 & 197 & 41.4 \\
\hline Total & $170 \mid$ & 583 & 34.2 \\
\hline
\end{tabular}

Table 2 Age range of the victims

\begin{tabular}{lll}
\hline Age Range (Years) & Frequency & Percent \\
\hline$\leq 10$ & 1 & 0.2 \\
$20-N o v$ & 146 & 25 \\
$21-30$ & 167 & 28.6 \\
$31-40$ & 119 & 20.4 \\
$41-50$ & 64 & 11 \\
$51-60$ & 53 & 9.1 \\
$61-70$ & 21 & 3.6 \\
$7 \mid-84$ & 12 & 2.1 \\
Total & 583 & 100 \\
\hline
\end{tabular}

High incidence of suicide in adolescence and young adults, a phenomenon, can be attributed to their emotional instability and impulsivity. This may be compounded by their love for experimentation with drug of addiction. Preponderance of young adult and adult can be due to the fact that this is the age when people face different challenges of life and stress to cope up the expectations of life and sociological and psychological problems causes them to commit poisoning victims. It is seen that there is very less difference in number of victims in terms of sex with females slightly outnumbering the males. This is in accordance with Kafley et al. ${ }^{16}$ and Prasad et al. ${ }^{17}$ Table 3 Out of the total 583 suicide cases autopsied included in the present study, little more than half (52.7\%) victims were females as compared to males $(47.3 \%)$ male: female ratio being 1:1.1. A higher rate of suicide by female have been reported in their studies by Shah, ${ }^{13}$ Satyavathi et al., ${ }^{12}$ and Singh et al., ${ }^{18}$ (1:1.9, 1:1.06 and 1:1.14). However, in general, the number of male suicide predominates over 
female in most of the countries of the world. Male: female ratio is believed to be 3:1 worldwide. A high female suicide rate as reported in this region can be attributed to the fact that many males are working outside the country for their livelihood and female are more involved in running the families and dealing with all the stress. Sometimes the women's near total dependence on their husbands and in-laws make them frequent victims of torture committing suicide Table 4.

Table 3 Sex of the victims

\begin{tabular}{lll}
\hline Sex & Frequency & Percent \\
\hline Female & 307 & 52.7 \\
Male & 276 & 47.3 \\
Total & 583 & 100 \\
\hline
\end{tabular}

Table 4 Marital status of victims

\begin{tabular}{lll}
\hline \multirow{2}{*}{ Sex } & \multicolumn{2}{l}{ Marital Status } \\
\cline { 2 - 3 } & Married & Unmarried \\
\hline Female & $245(80 \%)$ & $62(20 \%)$ \\
Male & $168(61 \%)$ & $108(39 \%)$ \\
Total & $413(71 \%)$ & $170(29 \%)$ \\
\hline
\end{tabular}

More than $2 / 3^{\text {rd }}(71 \%)$ of the total victims of suicide were married (Table 4) followed by unmarried (29\%). Female victims were more married (80\%) in comparison to male counterparts (61\%). The Police Research Bureau (1980) of India showed that amongst 76 suicide cases, 43 were married and 33 were unmarried. Dash SK et al. ${ }^{10}$ found most of victims to be married. Ramadwar et al., ${ }^{14}$ in their study found a much greater number of married individual amongst the suicide victims as compared to the unmarried (5:1) in Nagpur. Mukherjee ${ }^{19}$ from Calcutta reported a ratio of 3.2:1 between the married and unmarried suicide victims. Though it is difficult to comment, the fact may be that, married people face more stresses while maintaining his family with little resources. As regards to divorce/separated group, the percentage of cases were two per cent each. Although the sample size is small to comment, it may be due to the fact that acceptance of this group to social stream is poor and subsequently they experience more life events leading to suicide. Thus poisoning is more prevalent in married persons which may be due to increase socioeconomic and physical burden after marriage and birth of children.

In present study (Tables 5a,5b \& 5c) poisoning $(61.6 \%)$ and hanging $(31.6 \%)$ were found to be commonest cause of death constituting more than $95 \%$ of total suicide cases. Burn was found to be third most common cause constituting $4.1 \%$ and a single case was found to be cut throat $(0.2 \%)$. Due to easy availability and the thinking that poisoning will be less painful; poisoning is one of the commonest methods of suicide. There was no sexual preference in poisoning and hanging but as we see in Table 6 it was found that burn was method of suicide opted more by female than male (3.5:1). Total 3 females from India were autopsied and all 3 of them were burn victims. This finding was consistent with the statistics of $\mathrm{NCBI},{ }^{20}$ suicide by consuming poison (34.8\%), hanging $(32.2 \%)$, burns $(8.8 \%)$ and drowning $(6.7 \%)$ were the prominent means of committing suicides. Due to easy availability of poison materials, poisoning was preferred method for suicide. Rahim et al., ${ }^{7}$ Sharma et al., ${ }^{8}$ in their study had however showed that hanging was most common cause of death, which was slightly in disagreement with those of, present study. According to Sharma BR et al. ${ }^{8}$ females preferred self-immolation (burns) to end their own lives. According to statistics of $\mathrm{NCBI},{ }^{20}$ the pattern of suicides reported from 35 cities showed that Hanging (45.7\%), Poisoning $(21.3 \%)$ and burns $(13.2 \%)$ were the prominent means adopted by the suicide victims in the cities. This is in accordance to our study where $76.32 \%$ of poisoning cases occurred in rural area while $87 \%$ hanging took place in urban area. Overwhelming majority of cases when found was dead. ${ }^{21-22}$ This could be due to the fact that a person committing suicide makes sure he dies of his act. ${ }^{23-28}$

Table 5a Cause of death of victims

\begin{tabular}{lll}
\hline Cause of Death & Frequency & Percent \\
\hline Burn & 27 & 4.6 \\
Cut throat & 1 & 0.2 \\
Hanging & 196 & 33.6 \\
poisoning & 359 & 61.6 \\
Total & 583 & 100 \\
\hline
\end{tabular}

Table 5b Sex cause of death Cross-tabulation

\begin{tabular}{llllll}
\hline \multirow{2}{*}{ Sex } & \multicolumn{2}{l}{ Cause of Death } & \multicolumn{2}{l}{ Total } \\
\cline { 2 - 5 } & Burn & Cut Throat & Hanging & Poisoning & \\
\hline Female & 21 & 0 & 101 & 185 & 307 \\
Male & 6 & 1 & 95 & 174 & 276 \\
Total & 27 & 1 & 196 & 359 & 583 \\
\hline
\end{tabular}

Table 5c Community character cause of death

\begin{tabular}{llllll}
\hline \multirow{2}{*}{ Community } & \multicolumn{3}{l}{ Cause of Death } & \\
\cline { 2 - 5 } & Burn & $\begin{array}{l}\text { Cut } \\
\text { Throat }\end{array}$ & Hanging & Poisoning & Total \\
\hline Rural & 22 & 1 & 27 & 274 & 324 \\
Urban & 5 & 0 & 169 & 85 & 259 \\
Total & 27 & 1 & 196 & 359 & 583 \\
\hline
\end{tabular}

Table 6 Condition of the victim

\begin{tabular}{lll}
\hline Condition of Victim & Frequency & Percent \\
\hline Alive & 100 & 17.2 \\
Dead & 483 & 82.8 \\
Total & 583 & 100 \\
\hline
\end{tabular}

\section{Conclusion}

It is clear from the study that young adult females and males who are the most productive group of people in the society commit suicide by consumption of poison, hanging and burn. Intervention by the treatment has a very little role to save the life of such person so the causes of poisoning which are principally sociological and psychological has to be taken care of. Most of the victims are of poisoning followed by hanging. Therefore some policy has to be made to control the easy availability of the poison in the society. Proper counseling of the population to counteract with the stressful situations has to be done and also proper opportunity for the population to employment has to be generated so that the poverty is overcome. 


\section{Acknowledgments}

I would like to thank the BPKIHS Research Board for providing the permission for successful completion of the research project. The contributions of Mr. Manjul Bhandari, Mr. Ram Priti Sah (Technician), Mr. Naveen Sah (Technician), Mr. Ugranarayan Yadav, Mr. Jitendra Uraw and Mr. J P Uraw of the Department of Forensic Medicine and Toxicology, BPKIHS, Dharan, Nepal are appreciated.

\section{Conflicts of interest}

None.

\section{References}

1. Suicide. The free Dictionary. 2014.

2. Marc B. Etiology, methods and statistics of parasuicide. Encyclopedia of Forensic \& Legal Medicine. 2005;4:236.

3. Thapa B, Carlough MC. Suicide Incidence in the Lalitpur district of central Nepal. Tropical Doctor. 2000;30(4):200-203.

4. Franklin CA. Modi's Medical Jurisprudence and Toxicology. 21st edn. 1988.

5. H.M.G Methods \& Rate of Suicide in Nepal Office of Attorney General HMG. 1998.

6. Aaron R, Joseph A, Abraham S, et al. Suicides in young people in rural southern India. Lancet. 2004;363(9415):1117-1118.

7. Rahim M, Das TC. Mortuary Profile for Unnatural Deaths at Forensic Medicine. Bangladesh Medical Journal. 2009;38(2):44-47.

8. Sharma BR, Singh VP, Sharma R, et al. Unnatural Deaths in Northern India - A Profile. Journal of Indian Academy of Forensic Medicine. 2004;26(4):140-146.

9. Srivastava P, Som D, Nandy S, et al. Profile of postmortem cases conducted at a morgue of a tertiary care hospital in Kolkata. $J$ Indian Med Assoc. 2010;108(11):730-733.

10. Dash SK, Mohanty MK, Mohanty S, et al. Organophosphorus poisoning: victim specific analysis of mortality and morbidity. Med Sci Law. 2008;48(3):241-245.

11. Kafle KK, Nepal MK, Sharma SR, et al. Poisoning cases at TUTH Journal of Institute of Medicine. 1989;2:293-301.
12. Satyavathi K, Murthi Rao DLN. A study of suicide in Bangalore. Transactions of All India Institute of Mental Health. 1961;2:1-19.

13. Shah JH. Suicide in Saurashtra. Indian J Soc Work. 1961;21:167.

14. Ramadwar DK, Majumdar RD, Ketkar YA. An epidemetric study of suicides in Nagpur City for the quinquennium 1953 to 1957. Indian $J$ Public Health. 1969;13(13):144-149.

15. Gupta S. Study of suicides in medicolegal autopsies. Banaras Hindu University, India. 1984.

16. Kafle KK, Gyawali KK. Organophosphorus - commonest poisoning agent. Journal of Institute of Medicine. 1992;14:228-233.

17. Prasad PN, Karki P. Poisoning cases at TUTH emergency: A one year review. Journal of Institute of Medicine. 1997;19:18-24.

18. Singh K, Jain NR, Khullar BM. A Study of suicide in Delhi State. J Ind Med Assoc. 1971;57(11):412-418.

19. Mukherjee JB. Study of suicide in coroner's Calcutta for 5 years. Clinician. 1972;36(6).

20. Accidental and Suicidal deaths in India. National Crime Bureau of India, India. 2008.

21. Singh D, Jit I, Tyagi S. Changing trends in acute poisoning in Chandigarh Zone: A 25-year autopsy experience from a Tertiary Care Hospital in Northern India. Am J Forensic Med Pathol. 1999;20(2):203-210.

22. Pradhan S. Attempted suicide a study of socio demographic variable methods employed and associated mental disorders. 2000.

23. Dubey D, Tripathi CB. Suicide- A sociological study in Varanasi Area. 1999.

24. Thakuria PK, Barbhuiyan SI. A study of suicidal cases in medicolegal autopsy. Dysphrenia. 2014;5:62.

25. SpelmanW, Joseph. Suicide, a medical examiner's view. Legal Medicine Annual 105. 1969

26. Paudyal BP. Poisoning: pattern and profile of admitted cases in a hospital in central Nepal. JNMA J Nepal Med Assoc. 2005;44(159):92-96.

27. Das Gupta SM, Tripathi AR. A study of suicide in Varanasi-part I: some epidemiological aspects. Ind Med Gaz. 1973.

28. Veeraghavan V. Suicide and attempted suicides in the Union territory of Delhi. 1984;1-251. 